\title{
Practice Environments and Job Satisfaction in Patient- Centered Medical Homes
}

Shebnaz Alidina, $M P H, S D^{1}$

Meredith B. Rosenthal, $P b D^{1}$

Eric C. Schneider, $M D, M S c^{1-4}$

Sara J. Singer, $M B A, P b D^{1,4,5}$

Mark W. Friedberg, MD, MPP ${ }^{2-4}$

'Harvard School of Public Health, Boston, Massachusetts

${ }^{2}$ RAND Corporation, Boston,

Massachusetts

${ }^{3}$ Brigham and Women's Hospital, Boston, Massachusetts

${ }^{4}$ Harvard Medical School, Boston, Massachusetts

${ }^{5}$ Massachusetts General Hospital, Boston, Massachusetts

Conflicts of interest: Dr Friedberg bas received compensation from the US Department of Veterans Affairs for consultation related to the medical bome model and research support from the Patient-Centered Outcomes Researcb Institute via subcontract to the National Committee for Quality Assurance.

\section{CORRESPONDING AUTHOR}

Shehnaz Alidina, MPH, SD

170 Brookline Ave, Apt 330

Boston, MA 02215

sha248@mail.harvard.edu

\begin{abstract}
PURPOSE We undertook a study to evaluate the effects of medical home transformation on job satisfaction in the primary care setting.

METHODS We collected primary data from 20 primary care practices participating in medical home pilot projects in Rhode Island and Colorado from 2009 to 2011. We surveyed clinicians and staff about the quality of their practice environments (eg, office chaos, communication, difficulties in providing safe, highquality care) and job satisfaction at baseline and 30 months, and about stress, burnout, and intention to leave at 30 months. We interviewed practice leaders about the impact of pilot project participation. We assessed longitudinal changes in the practice environment and job satisfaction and, in the final pilot year, examined cross-sectional associations between the practice environment and job satisfaction, stress, burnout, and intention to leave.
\end{abstract}

RESULTS Between baseline and 30 months, job satisfaction improved in Rhode Island $(P=.03)$ but not in Colorado. For both pilot projects, reported difficulties in providing safe, high-quality care decreased $(P<.001)$, but emphasis on quality and the level of office chaos did not change significantly. In cross-sectional analyses, fewer difficulties in providing safe, high-quality care and more open communication were associated with greater job satisfaction. Greater office chaos and an emphasis on electronic information were associated with greater stress and burnout.

CONCLUSIONS Medical home transformations that emphasize quality and open communication while minimizing office chaos may offer the best chances of improving job satisfaction.

Ann Fam Med 2014;331-337. doi: 10.1370/afm.1662.

\section{INTRODUCTION}

$\mathrm{P}$ rimary care can improve health outcomes and the overall performance of the health system. ${ }^{1,2}$ Primary care physicians, however, report lower job satisfaction than other physicians, ${ }^{3}$ and job dissatisfaction has been identified as a potential cause and result of quality problems in physician practices. ${ }^{4}$ Improving the practice work environment may enhance primary care job satisfaction..$^{4-7}$

In theory, patient-centered medical homes (PCMHs, or medical homes) improve job satisfaction by promoting better work environments, increasing the quality of care, and enhancing practice resources. ${ }^{7.9}$ In theory, medical homes combine the 4 principles of primary care (first contact with the health system, continuity of care with a personal physician, a focus on the whole person, and coordination of care across the continuum), with an emphasis on care that is patient centered, team based, evidence based, and optimized through information technology. ${ }^{10}$ The ability of medical home interventions to achieve their goals, including improved professional satisfaction, is subject to empirical evaluation, however. ${ }^{11,12}$

Better job satisfaction (specifically, lower burnout) has been reported in a single-practice pilot project conducted within the Group Health Cooperative. ${ }^{13}$ These findings have not yet been replicated elsewhere, and the specific factors that may mediate medical home effects on job satisfaction have 
not been identified. To address these gaps, we focused our study on 3 main goals. First, we evaluated longitudinal effects of 2 medical home pilot projects on multiple dimensions of practice environment and job satisfaction. Second, at the conclusion of these projects, we explored cross-sectional relationships between dimensions of practice context and clinician and staff satisfaction, stress, burnout, and intention to leave. Third, we sought to understand the benefits and challenges of medical home transformation using qualitative methods.

Published research identifies 3 main aspects of the practice environment affecting job satisfaction in primary care. First, clinicians and staff are more satisfied when their organizational cultures emphasize quality

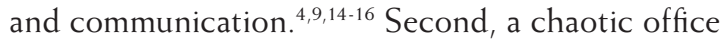
atmosphere is associated with job dissatisfaction and stress. ${ }^{6,7}$ Third, clinicians and staff are less satisfied when they face difficulties in providing safe, highquality care. ${ }^{4,9}$

Our study addressed 2 related hypotheses (Figure 1). First, medical home pilot practices would report improvements over time in practice environment and job satisfaction. Second, at each pilot project's conclusion, practices with better practice environments (ie, lower levels of chaos and difficulty providing safe, high-quality care) would have greater job satisfaction and lower stress, burnout, and intention to leave.

\section{METHODS}

\section{Study Sample}

We collected data at baseline and 30 months from 20 primary care practices participating in medical home pilot projects in Rhode Island (5 practices, 28 physicians) and Colorado (15 practices, 50 physicians). Rhode Island and Colorado were 2 of the earliest multipayer PCMH initiatives and therefore were selected by the Commonwealth Fund for evaluation. Although both pilot projects targeted small to medium-sized practices (9 or fewer physicians), they had different payer and clinician environments.

The Rhode Island Chronic Care Sustainability Project (Rhode Island pilot project), convened by the state and 3 major commercial payers, began in October 2008 and ran 3 years. Each practice received a monthly fee of $\$ 3$ to $\$ 4.50$ per member based on its PCMH recognition level (from the National Committee for Quality Assurance [NCQA]), financial support for a nurse care manager, assistance from a "transformation coach," and opportunities to participate in learning collaboratives.

The HealthTeamWorks initiative (Colorado pilot project), convened by HealthTeamWorks and 7 commercial and Medicaid payers, began in May 2009 and lasted 3 years. Each practice received a fee of $\$ 4$ to $\$ 8$ per member based on its PCMH recognition level (from the NCQA), performance-based payments, transformation coaching, and learning collaborative sessions.

The design elements and changes implemented by the practices from baseline to 30 months in both pilot projects are shown in Supplemental Appendixes 1 and 2.

\section{Survey Instrument}

We designed a written survey instrument to collect information on 3 aspects of the practice environment: organizational culture, office chaos, and difficulties in providing safe, high-quality care.

We assessed organizational culture by asking respondents to assess their practice's emphasis on quality (5 items; Cronbach $\alpha=0.90$ ), electronic information ( 2 items; Spearman correlation $=0.77$ ), and open communication between clinicians and staff (1 item). Questions came from the Quality Emphasis and the Information and Communication Emphasis scales of the Minimizing Error, Maximizing Outcomes (MEMO) clinician survey instrument. ${ }^{6,7}$ Office chaos was measured using a single MEMO item rating the office atmosphere from "calm" to "chaotic." ${ }^{\text {"7 }}$ We measured difficulties providing safe and high-quality care by drawing 2 items from a prior survey of Massachusetts primary care practices (Spearman correlation $=0.75) .{ }^{17}$

The survey instrument included 4 outcome measures: job satisfaction, stress, burnout, and intention to leave. Job satisfaction was measured at baseline (wave 1) and 30 months (wave 2) using a single item assessing global job satisfaction. Stress, burnout, and intention to leave were measured at 30 months only. For burnout, we used 1 item highly correlated with the Maslach Burnout Inventory. ${ }^{18}$ For intention to leave, we asked respondents about their likelihood of leaving a practice within 2 years. The survey instrument appears in Supplemental Appendix 3.

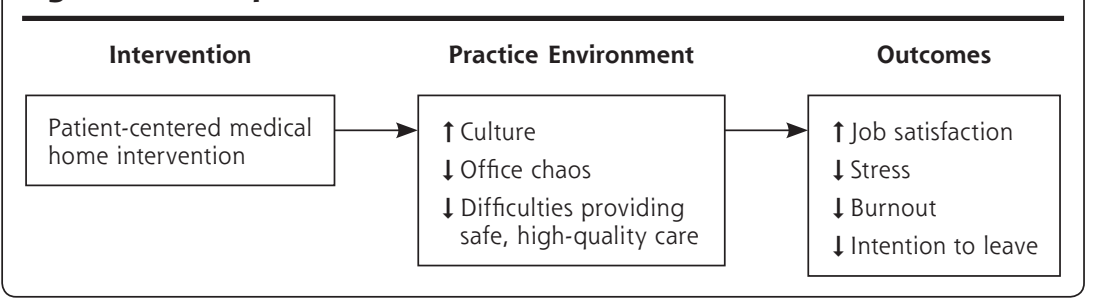

\section{Survey Administration}

We administered the clinician and staff surveys for both waves by mailing and e-mailing questionnaires to each pilot practice 
leader, who distributed them to clinicians and staff. All clinicians (physicians, physician assistants, and nurse practitioners) and other staff (medical assistants, care coordinators, nurses, office managers, and administrative support staff) in these practices were eligible to receive the questionnaires.

\section{Interviews}

We conducted 3 sets of hour-long, semistructured interviews with practice leaders at baseline, 18 months, and 30 months. Practice leaders were physicians responsible for spearheading transformation efforts and often held formal leadership roles, although some were informal champions of medical home transformation.

Each interview was conducted by at least 2 authors and included open-ended questions exploring the effects of medical home transformation on job satisfaction and related constructs. Specific questions evolved across the interview waves, congruent with progression of the medical home pilots. The interview protocols appear in Supplemental Appendix 4.

\section{Data Analysis}

To assess longitudinal differences in survey responses, we created dichotomous variables using previous MEMO thresholds ${ }^{6}$ or median responses. We assessed differences in responses at baseline and at 30 months using Fisher exact tests with significance at $P<.05$. In longitudinal analyses, standard errors could not account for clustering by physician practice, because practice identifiers were absent from the baseline survey responses.

In cross-sectional analyses of survey responses in the final year of each pilot project, we fit logistic regression analyses with job satisfaction, stress, burnout, and intention to leave as the dependent variables, and characteristics of the practice environment (organizational culture, office chaos, and difficulties in providing safe, high-quality care) as the independent variables, controlling for sex, employment length, and pilot project as potential confounders. For stress, burnout, and intention to leave, we used dichotomous variables based on thresholds established by Linzer et al. ${ }^{7}$ We used generalized estimating equations to account for clustering of observations within practices. ${ }^{19}$ All statistical analyses were performed using SAS version 9.3 (SAS Institute).

We analyzed the qualitative data using thematic analysis. ${ }^{20}$ First, we agreed on a coding scheme that reflected 3 main categories in our conceptual framework: organizational culture, office chaos, and difficulties providing safe, high-quality care. One author (S.A.) then coded interview transcript data using ATLAS.ti version 6.2 qualitative software (ATLAS.ti $\mathrm{GmbH}$ ), clarifying coding decisions as needed with the other authors. We established coding reliability with a second, independent coder for approximately $15 \%$ of the transcripts $(\kappa=0.86$, percent agreement $=0.90)$.

After completing the initial coding, we sorted the data by code to identify similarities and differences across cases. All investigators discussed and refined preliminary results of the qualitative analysis and compared these with results from the quantitative data. Finally, we selected quotes to illustrate the key themes that emerged from the interviews.

The study was approved by institutional review boards at the Harvard School of Public Health and RAND.

\section{RESULTS}

Survey response rates were $61 \%$ at baseline and $80 \%$ at 30 months. (The sample size changed between time points because of the hiring of care coordinators and considerable growth in one of the practices.) Practice and respondent characteristics at baseline are summarized in Table 1.

\section{Effects of Medical Home Pilot Project Participation}

The effects of medical home pilot project participation on organizational culture, office chaos, difficulties in the practice environment, and job satisfaction are summarized in Table 2. Key themes and illustrative interview quotes on the perceived benefits and challenges associated with transformation to PCMHs appear in Table 3.

\section{Practice Environment}

Project participation was associated with a reduction in the percentage of respondents who reported "sometimes" or "frequently" experiencing difficulties providing safe, high-quality care at 30 months $(P<.001)$. There also were trends, which did not reach statistical significance, toward stronger emphasis on quality $(P=.06)$ and increasing office chaos $(P=.15)$ between baseline and 30 months.

In interviews, practice leaders described developing greater ability to provide high-quality care and adopting longitudinal, team-based approaches to serving chronically ill patients. Additional workload, implementation hurdles, underdeveloped technology, and change fatigue were noted as potential detractors from job satisfaction, however.

\section{Job Satisfaction}

Averaged across clinician and staff categories, job satisfaction had increased at 30 months in the Rhode Island pilot project $(P=.03)$ but not in the Colorado pilot project. Combining both projects, there was 
Table 1. Characteristics of Practices and Survey Respondents at Baseline

\begin{tabular}{|c|c|c|}
\hline Characteristic & \multicolumn{2}{|c|}{$\begin{array}{c}\text { Practices }(\mathrm{N}=20) \\
\text { No. }(\%)\end{array}$} \\
\hline \multicolumn{3}{|l|}{ Practices } \\
\hline \multicolumn{3}{|l|}{ Pilot project } \\
\hline Rhode Island & \multicolumn{2}{|l|}{$5(25)$} \\
\hline Colorado & \multicolumn{2}{|l|}{$15(75)$} \\
\hline \multicolumn{3}{|l|}{ Type } \\
\hline Private, stand-alone practice & \multicolumn{2}{|l|}{$17(85)$} \\
\hline $\begin{array}{l}\text { Federally qualified health } \\
\text { center }\end{array}$ & \multicolumn{2}{|l|}{$1(5)$} \\
\hline System-owned practice & \multicolumn{2}{|l|}{$2(10)$} \\
\hline Affiliated with an IPA & \multicolumn{2}{|l|}{$10(50)$} \\
\hline \multicolumn{3}{|l|}{ Practice size } \\
\hline Solo practice & \multicolumn{2}{|l|}{$4(20)$} \\
\hline 2-3 physicians & \multicolumn{2}{|l|}{$8(40)$} \\
\hline 4-8 physicians & \multicolumn{2}{|l|}{$8(40)$} \\
\hline \multicolumn{3}{|l|}{ NCQA PCMH recognition level } \\
\hline Level 1 & \multicolumn{2}{|l|}{$3(15)$} \\
\hline Level 2 & \multicolumn{2}{|l|}{$3(15)$} \\
\hline Level 3 & \multicolumn{2}{|l|}{$14(70)$} \\
\hline \multicolumn{3}{|l|}{ Specialty } \\
\hline Family medicine & \multicolumn{2}{|l|}{$16(80)$} \\
\hline Internal medicine & \multicolumn{2}{|l|}{$4(20)$} \\
\hline Survey respondents & $\begin{array}{l}\text { Baseline, } \\
\text { No. (\%) }\end{array}$ & $\begin{array}{l}30 \text { Mo, } \\
\text { No. (\%) }\end{array}$ \\
\hline Total respondents & $101(61)$ & $251(80)$ \\
\hline \multicolumn{3}{|l|}{ Respondent type } \\
\hline Physicians & $56(55)$ & $80(32)$ \\
\hline $\begin{array}{l}\text { Physician assistants and nurse } \\
\text { practitioners }\end{array}$ & $16(16)$ & $22(9)$ \\
\hline Nonclinical office staff & $29(29)$ & $149(59)$ \\
\hline Sex, female & $61(60)$ & $208(83)$ \\
\hline \multicolumn{3}{|l|}{ Average length of employment } \\
\hline$\leq 2 \mathrm{y}$ & $34(34)$ & $80(32)$ \\
\hline$>2 y$ & $66(66)$ & $171(68)$ \\
\hline
\end{tabular}

IPA = independent practice association; NCQA = National Committee for Quality Assurance; PCMH = patient-centered medical home.

nonsignificant improvement in job satisfaction among primary care physicians and nonclinical staff, and a nonsignificant trend toward worsening job satisfaction among nurse practitioners and physician assistants.

In interviews, practice leaders rated job satisfaction from very positive to neutral. They identified an increased ability for primary care physicians to concentrate on practicing medicine as a key contributor to job satisfaction. Leaders also reported greater staff satisfaction, which they attributed to empowerment. The changes in responsibilities related to the transformation were also challenging, however. For example, not all medical assistants coped well with adding new tasks and responsibilities to their existing duties, resulting in the departure of some staff.
Table 2. Changes in the Practice Environment and Job Satisfaction at Baseline and 30 Months

\begin{tabular}{|c|c|c|c|}
\hline Variable & $\begin{array}{l}\text { Baseline } \\
\%\end{array}$ & $\begin{array}{c}30 \text { Months } \\
\%\end{array}$ & $\begin{array}{c}P \\
\text { Value }\end{array}$ \\
\hline \multicolumn{4}{|c|}{ Organizational culture ("to a great extent") } \\
\hline Quality emphasis ${ }^{b}$ & 24 & 35 & .06 \\
\hline $\begin{array}{l}\text { Electronic information } \\
\text { emphasis }^{\mathrm{b}}\end{array}$ & 64 & 63 & .90 \\
\hline Open communication ${ }^{b}$ & 51 & 44 & .24 \\
\hline $\begin{array}{l}\text { Hectic or chaotic office } \\
\text { level }^{\text {c }}\end{array}$ & 34 & 42 & .15 \\
\hline $\begin{array}{l}\text { Difficulties in providing } \\
\text { safe, high-quality } \\
\text { care ("sometimes"I } \\
\text { "frequently") }\end{array}$ & 30 & 14 & .001 \\
\hline \multicolumn{4}{|c|}{ Job satisfaction ("agree"I"strongly agree")e } \\
\hline \multicolumn{4}{|c|}{ By pilot project, respondents overall } \\
\hline Rhode Island & 67 & 86 & .03 \\
\hline Colorado & 86 & 80 & .42 \\
\hline \multicolumn{4}{|c|}{ By respondent type, pilot projects combined } \\
\hline Physicians & 71 & 78 & .49 \\
\hline $\begin{array}{l}\text { Nurse practitioners and } \\
\text { physician assistants }\end{array}$ & 90 & 76 & .41 \\
\hline Nonclinical office staff & 76 & 84 & .32 \\
\hline \multicolumn{4}{|c|}{ MEMO = Minimizing Error, Maximizing Outcomes } \\
\hline $\begin{array}{l}\text { a Compared with "not at all"/"a } \\
\text { b Dichotomized based on med } \\
\text { " Dichotomized based on <4 a } \\
\text { d Compared with "never"/"rare } \\
\text { e Compared with "strongly disa }\end{array}$ & $\begin{array}{l}\text { tle"I"to a consic } \\
\text { responses. } \\
\geq 4 \text { based on N } \\
\text { ee"/"disagree"/" }\end{array}$ & $\begin{array}{l}\text { Erable extent." } \\
\text { EMO approach. } \\
\text { heither agree nor }\end{array}$ & agree." \\
\hline
\end{tabular}

Stress, Burnout, and Intention to Leave

At 30 months, about one-half of the respondents perceived their jobs to be moderately stressful, while about one-quarter reported highly stressful jobs, high levels of burnout, and a moderate or greater likelihood of leaving their practices within 2 years, as shown in Table 4 .

\section{Associations of Practice Environment With Clinician and Staff Outcomes}

Table 5 shows the multivariate cross-sectional associations between dimensions of the practice environment and job satisfaction, stress, burnout, and intention to leave at 30 months. More open communication between clinicians and staff was associated with greater satisfaction and less burnout; greater emphasis on electronic information was associated with more stress and burnout. A 1-point increase in electronic information emphasis was associated with a nearly $50 \%$ increase in the odds of experiencing stress and a 2 -fold increase in the odds of experiencing burnout.

Office chaos had large, significant associations with poor work experiences. A 1-point increase in office chaos was associated with a more than a 3 -fold increase in the odds of experiencing high levels of stress and burnout and a $60 \%$ increase in the odds of intend- 
Table 3. Key Themes Emerging as Benefits and Challenges of Medical Home Transformation

\section{Benefits \\ Culture of quality \\ "I'm a good doctor, I work very hard. I keep up with the literature. I didn't think measurement would make a difference. It was a striking and difficult experience when I realized I wasn't doing as good a job as I thought, as measured...If you assume you are doing a good job، you are leaving the door wide open for not doing a good job. If you measure and improve at whatever level you start...that's the part that's far more inspiring." \\ "Value depends on quality improvement. This is one of the most moti- vating pieces in becoming a PCMH. Power of measurement, data collection from one's own practice, compared to benchmarks to see areas of competence, areas of improvement, areas of weakness-to guide improvement."}

\section{Increased ability to provide safe, high-quality care}

"The non-PCMH is episodic. The patient comes in to do something and the patient leaves...If they don't come back, then they just stay gone. What we're doing now...they're not gone in between visits. Their orders are being tracked. If their results don't come in, we notice. There are team members who are interacting with them in between visits, so they get a follow-up phone call. We're also tracking outcomes...That is a very different model of care that feels a whole lot better."

"The core is improved quality of care, more aggressive management of chronic disease, more aggressive preventive care-being that place where patients feel they can go and are cared about. Really trying to reduce those unnecessary complications of poorly managed chronic disease. In the past, when we had paper charts, we would just wait for patients to come and see us... Now with our EMR, with a click of a button we have a full registry of our diabetic patients and we are doing the same thing with other diseases as well. That's the core of it."

\section{Meaningful work for physicians}

"My colleagues would tell you that they are doing a lot more medicine and more patient care and less of the filling out forms, and more of taking care of people, which is why we went into medicine in the first place. So, on average I think it has been a very positive experience."

"I can think of 2 physicians who told me that they would have retired from primary care if it were not for this project...[T]hey do feel like they are being better compensated...spending more of their time doing doctoring and less of their time doing things that they don't consider to be at the top of their training."

\section{Meaningful work for staff/staff empowerment}

"The people who work our registries see the fruits of their labor...one [patient] in particular was reminded about getting a mammogram and proved to have cancer 3 months after the test was ordered. That particular MA understands that this new type of work for her probably helped save a patient's life. That is powerful stuff."

"The dramatic difference in our practice was the engagement of our staff to be independent thinkers in patient care. Every staff member feels a part of the patient's care, feels responsible...When a medical assistant sees an abnormal lab, he or she brings it to the doc's attention instead of just assuming the doc will notice it."

\section{Challenges}

Challenges in implementing electronic information systems

"We've had to jerry-rig our own ways of getting this stuff out and reported. On my really bad days when I am frustrated, I worry that our data might not be that accurate because of all that jerryrigging. We at least have gone out of our way to really doubleand triple-check stuff manually to make sure that we have the right data reported and data entered."

"The challenges of our EMR should not be underestimated. My staff has come along with it, but it has just been a frustrating challenge to keep that system working right...I think there is some burnout there [among the staff]; there is for me too. It's just been a challenging system at times."

\section{Increased workloads}

"To transfer from a paper-based practice to electronic is a huge undertaking...People who take that on are really brave souls. That transition is harder than you plan, takes longer and more man hours."

"I thought we could just lay this out and start doing something new...And it really takes a lot of work and a lot of time...Even if someone has a really good idea of how to do it, you still have to make your changes on the local level, figure out how it's going to work for you."

\section{Transformation in roles and responsibilities}

"I see our physicians as being significantly stressed by practicing in this environment and to some extent they may have traded in some of the old frustrations for the change management frustrations of a moving target...With so much change, whose job is it and whose job is it today?"

"Now, all of a sudden, we've taken people who have just taken orders and made them responsible for patient care. They're not used to that kind of responsibility and accountability. That takes some character and personality, and there's a lot of stress that goes along with that."

\section{Change fatigue}

"We haven't had [change fatigue] in the past, but we are beginning to have it now as we are adding more disease registries. When we only had 1 disease registry, it was easy to keep it up to date. Now that we are trying to do 3 or more, it's that much more additional work on all of the staff and they get a little frustrated."

"I do get change fatigue. But, when you are the only physician champion, you can't really afford to show it...It will be a lot easier for practices years from now who are starting up their $\mathrm{PCMH}$. They are going to have a guidebook they can follow... But for us, making the change is definitely very trying."

\section{Lack of broader payment reform}

"There is just more stuff to do on this really fast-moving hamster wheel. That's our problem. We need to figure out a way to get paid and get a way to engage patients...When we can move to a system where we can do more, say, phone management, engage patients in other ways that don't require the time intensity that we have now. I think that is going to be what will be helpful."

$\mathrm{EMR}=$ electronic medical record; $\mathrm{MA}=$ medical assistant; $\mathrm{PCMH}=$ patient-centered medical home.

ing to leave the practice within 2 years. Difficulties in providing safe, high-quality care were associated with lower job satisfaction and greater stress, burnout, and intention to leave.

\section{DISCUSSION}

In our study of medical home pilot projects in Rhode Island and Colorado, we found inconsistent changes in job satisfaction. For the 2 pilot projects combined, there were no statistically significant changes in job satisfaction; however, there was significant improvement in job satisfaction in the Rhode Island project and a modest, nonsignificant decline in satisfaction in the Colorado project. What explains these different results? First, baseline levels of job satisfaction were higher in Colorado, leaving less room to improve. Second, our qualitative data suggest that Colorado's transformation work was more intensive, which could have created a "worse before better" scenario, like that described in evaluations of the TransforMed National Demonstration Project. ${ }^{21}$ 
Table 4. Respondent Stress, Burnout, and Intention to Leave in Practices at $\mathbf{3 0}$ Months

\begin{tabular}{|c|c|}
\hline Variable & Respondents, \% \\
\hline \multicolumn{2}{|l|}{ Job stress ${ }^{a}$} \\
\hline Above neutral stress ( $\geq 3.5)$ & 47.8 \\
\hline High stress $(\geq 4)$ & 27.5 \\
\hline \multicolumn{2}{|l|}{ Burnouta } \\
\hline Definitely burning out $(\geq 3)$ & 22.6 \\
\hline Persistently or completely burned out $(\geq 4)$ & 8.9 \\
\hline \multicolumn{2}{|l|}{ Intention to leave clinic within $2 y^{a}$} \\
\hline $\begin{array}{l}\text { Moderate or greater likelihood of leaving } \\
\text { practice leaving }(\geq 3)\end{array}$ & 22.5 \\
\hline \multicolumn{2}{|c|}{$\begin{array}{l}\text { a Dichotomized using cut points from Linzer et al. }{ }^{7} \text { Scales: stress, } 1-5(1=\text { less } \\
\text { job stress, } 5=\text { high job stress); burnout, } 1-5(1=\text { no symptoms of burnout, } \\
5=\text { completely burned out }) \text {; and intention to leave within } 2 \text { years, } 1-5 \\
(1=\text { none, } 5=\text { definitely). }\end{array}$} \\
\hline
\end{tabular}

Our findings suggest that the theoretical benefits of medical homes for clinicians and staff professional satisfaction may have been opposed by the stresses of transformation. For example, practices exhibited increasing emphasis on quality and fewer problems in providing safe, high-quality patient care. Such changes would be expected to enhance satisfaction, however, other trends seen among the practices-notably, greater office chaos-may have prevented greater job satisfaction from taking hold. Moreover, strategies aimed at reducing stress, such as reduced panel sizes, longer patient visit times, and dedicated time for care coordination (which have been featured in some medical home interventions ${ }^{13}$ ) were not included in the interventions we studied. These and similar transformation components may be necessary to foster better clinician experiences on a short timeline.

In general, fee-for-service payment does not compensate primary care physicians for non-visit-based care or coordination of care. ${ }^{22}$ The incentives provided in the pilot projects we studied may have been insufficient to encourage physicians to reduce office visit volumes while redesigning their practice. Broader pay- ment reform may be essential for enabling transformation without increasing office chaos.

Finally, baseline levels of stress, burnout, and intention to leave were slightly lower than those previously found by Linzer et al. ${ }^{7}$ The practices we studied volunteered for early medical home pilot projects and so may have been better off at baseline than other practices, leaving relatively little room for improvement.

Our cross-sectional results suggest how medical home interventions can increase their chances of improving job satisfaction in primary care. Interventions that reduce difficulties in providing safe, highquality care without increasing office chaos may offer the best chance of improving job satisfaction. The associations we observed between a quality emphasis, fewer quality problems, and job satisfaction corroborate research showing associations between greater engagement in quality-improvement activities, higher physician satisfaction, and less work-life stress. ${ }^{9}$ Similar to Hall et $\mathrm{al}_{1}{ }^{23}$ we found that a culture of open communication was associated with greater job satisfaction and less burnout. As suggested by other studies, ${ }^{7}$ our cross-sectional analysis found that greater office chaos was a key driver of dissatisfaction. Finally, we found associations between greater emphasis on electronic communication and increased stress and burnout, similar to findings of other recent studies., ${ }^{4,24}$

Our study has limitations. First, our sample size was small, limiting the power to detect longitudinal effects of project participation. Second, the observational nature of both our longitudinal and crosssectional analyses limits causal inference. Third, no control practices were surveyed or interviewed about job satisfaction, so we cannot exclude the possibility that our longitudinal results are attributable to changes in primary care practice other than a medical home intervention. Fourth, practices in our study volunteered to be pilot project sites, and our findings may not generalize to later adopters of new practice models. Fifth, the 2 pilot projects we studied were

Table 5. Associations of the Practice Environment With Clinician and Staff Outcomes at 30 Months

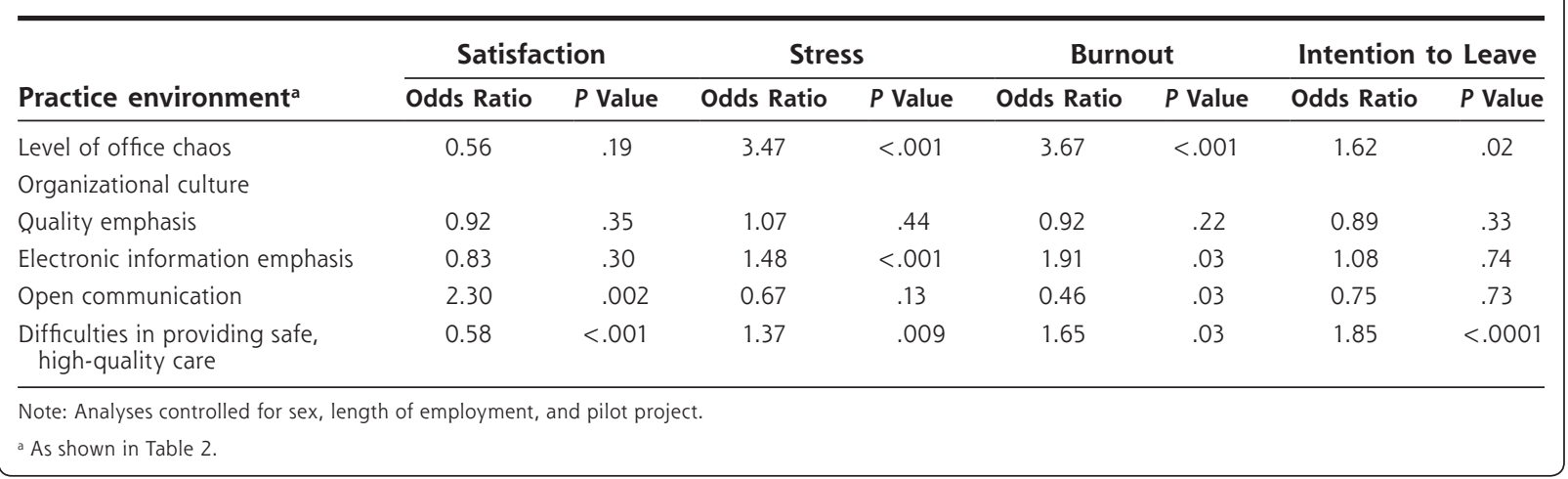


administered by different entities and had multiple different intervention components, limiting our ability to compare the interventions directly on any single component. Sixth, we measured global job satisfaction only, limiting our ability to make inferences about subdimensions of job satisfaction. Finally, we interviewed only practice leaders, and this sampling may have yielded an incomplete or skewed perception of advances in the practice environment (ie, a rosier picture than front-line clinicians would paint).

Improving job satisfaction in primary care practices is an important goal of medical home interventions. Our findings suggest that medical home transformations that emphasize quality and open communication while minimizing office chaos may offer the best chances of improving job satisfaction.

\section{To read or post commentaries in response to this article, see it online at http://www.annfammed.org/content/12/4/331.}

Key words: patient-centered medical home; job satisfaction; practice environment; primary care; quality culture; office chaos; transformation; practice-based research

Submitted October 25, 2013; submitted, revised, March 25, 2014; accepted April 1, 2014.

\begin{abstract}
Acknowledgments: The authors gratefully acknowledge the individuals who participated in this research. We would also like to acknowledge the invaluable assistance of Dr Mark Linzer and Dr Roger Brown in constructing subscales from the Minimizing Errors/Maximizing Outcomes clinician survey instruments, Dr E. John Orav for his statistical guidance, and Ms Diana Eastman for administering the surveys and transcribing the interviews.
\end{abstract}

Funding support: Shehnaz Alidina's effort on this project was supported by dissertation grants from the Canada Program of the Weatherhead Center for International Affairs and from the Canadian Federation of University Women. Funding for the study as a whole and for the effort of Meredith Rosenthal, Eric Schneider, Sara Singer, and Mark Friedberg was provided by the Commonwealth Fund.

Supplementary materials: Available at http://www.AnnFamMed. org/content/12/4/331/suppl/DC1/

\section{References}

1. Starfield B, Shi L, Macinko J. Contribution of primary care to health systems and health. Milbank Q. 2005;83(3):457-502.

2. Friedberg MW, Hussey PS, Schneider EC. Primary care: a critical review of the evidence on quality and costs of health care. Health Aff (Millwood). 2010;29(5):766-772.

3. Leigh JP, Tancredi DJ, Kravitz RL. Physician career satisfaction within specialties. BMC Health Serv Res. 2009;9:166.

4. Friedberg MW, Chen PG, Van Busum KR, et al. Factors Affecting Physician Professional Satisfaction and Their Implications for Patient Care, Health Systems, and Health Policy. Santa Monica, CA: RAND Corporation; 2013. http://www.rand.org/pubs/research_reports/RR439.html.

5. Williams ES, Konrad TR, Linzer M, et al; SGIM Career Satisfaction Study Group. Physician, practice, and patient characteristics related to primary care physician physical and mental health: results from the Physician Worklife Study. Health Serv Res. 2002;37(1):121-143.
6. Linzer M, Manwell LB, Mundt M, et al. Organizational climate, stress, and error in primary care: the MEMO Study. In: Henriksen K, Battles JB, Marks ES, Lewin DI, eds. Advances in Patient Safety: From Research to Implementation (Volume 1: Research Findings). Rockville, MD: Agency for Healthcare Research and Quality; 2005. Publication No. 05-0021-1.

7. Linzer M, Manwell LB, Williams ES, et al. Working conditions in primary care: physician reactions and care quality. Ann Intern Med. 2009;151(1):28-36, W6-W9.

8. Hauer KE, Durning SJ, Kernan WN, et al. Factors associated with medical students' career choices regarding internal medicine. JAMA. 2008;300(10):1154-1164.

9. Quinn MA, Wilcox A, Orav EJ, Bates DW, Simon SR. The relationship between perceived practice quality and quality improvement activities and physician practice dissatisfaction, professional isolation, and work-life stress. Med Care. 2009;47(8):924-928.

10. Bodenheimer T, Pham HH. Primary care: current problems and proposed solutions. Health Aff (Millwood). 2010;29(5):799-805.

11. Friedberg MW, Lai DJ, Hussey PS, Schneider EC. A guide to the medical home as a practice-level intervention. Am J Manag Care. 2009;15(10 Suppl):S291-S299.

12. Friedberg MW. The potential impact of the medical home on job satisfaction in primary care. Arch Intern Med. 2012;172(1):31-32.

13. Reid RJ, Coleman K, Johnson EA, et al. The Group Health medical home at year two: cost savings, higher patient satisfaction, and less burnout for providers. Health Aff (Millwood). 2010;29(5):835-843.

14. Zazzali JL, Alexander JA, Shortell SM, Burns LR. Organizational culture and physician satisfaction with dimensions of group practice. Health Serv Res. 2007;42(3 Pt 1):1150-1176.

15. Brazil K, Wakefield DB, Cloutier MM, Tennen H, Hall CB. Organizational culture predicts job satisfaction and perceived clinical effectiveness in pediatric primary care practices. Health Care Manage Rev. 2010;35(4):365-371.

16. Lewis SE, Nocon RS, Tang H, et al. Patient-centered medical home characteristics and staff morale in safety net clinics. Arch Intern Med. 2012;172(1):23-31.

17. Friedberg MW, Safran DG, Coltin KL, Dresser M, Schneider EC. Readiness for the patient-centered medical home: structural capabilities of Massachusetts primary care practices. J Gen Intern Med. 2009;24(2):162-169.

18. Rohland BM, Kruse GR, Rohrer JE. Validation of a single-item measure of burnout against the Maslach Burnout Inventory among physicians. Stress Health. 2004;20(2):75-79.

19. Liang K-Y, Zeger SL. Longitudinal data analysis using generalized linear models. Biometrika. 1986;73(1):13-22.

20. Boyatzis RE. Transforming Qualitative Information: Thematic Analysis and Code Development. Thousand Oaks, CA: Sage Publications; 1998.

21. Nutting PA, Miller WL, Crabtree BF, Jaen CR, Stewart EE, Stange KC. Initial lessons from the first national demonstration project on practice transformation to a patient-centered medical home. Ann Fam Med. 2009;7(3):254-260.

22. Berenson RA, Rich EC. US approaches to physician payment: the deconstruction of primary care. J Gen Intern Med. 2010;25(6): 613-618.

23. Hall CB, Brazil K, Wakefield D, Lerer T, Tennen H. Organizational culture, job satisfaction, and clinician turnover in primary care. J Prim Care Community Health. 2010;1(1):29-36.

24. Babbott S, Manwell LB, Brown R, et al. Electronic medical records and physician stress in primary care: results from the MEMO Study. J Am Med Inform Assoc. 2014;21(e1):e100-e106. 